Research Article

\title{
Electrochemical Deposition of $U$ and RE Elements Using the Stirred Liquid Cadmium Cathode in LiCl-KCl Molten Salts
}

\author{
Gha-Young Kim $\mathbb{D}^{1},{ }^{1}$ Chang Hwa Lee $\mathbb{D}^{2},{ }^{2}$ Dalsung Yoon $\mathbb{D D}^{2}$ Junhyuk Jang $\mathbb{D}^{1}{ }^{1}$ \\ and Sung-Jai Lee $\mathbb{i D}^{2}$ \\ ${ }^{1}$ Disposal Performance Demonstration Research Division, Korea Atomic Energy Research Institute, \\ Daejeon 34057, Republic of Korea \\ ${ }^{2}$ Nuclear Fuel Cycle Process Research Division, Korea Atomic Energy Research Institute, Daejeon 34057, Republic of Korea
}

Correspondence should be addressed to Gha-Young Kim; gkim@kaeri.re.kr

Received 21 June 2021; Revised 1 October 2021; Accepted 4 October 2021; Published 28 October 2021

Academic Editor: Peter Ivanov

Copyright ( $) 2021$ Gha-Young Kim et al. This is an open access article distributed under the Creative Commons Attribution License, which permits unrestricted use, distribution, and reproduction in any medium, provided the original work is properly cited.

\begin{abstract}
This study was conducted in an attempt to understand the effect of a stirred liquid cadmium cathode (LCC) on the electrodeposition of $\mathrm{U}$ and $\mathrm{U} / \mathrm{RE}$ on Cd. For this purpose, a series of electrowinning tests were performed using an LCC equipped with a $\mathrm{Cd}$ stirrer. Initially, three runs of the $\mathrm{U}$ electrodeposition tests were conducted using $\mathrm{LiCl}-\mathrm{KCl}-\mathrm{UCl}_{3}$ at $500^{\circ} \mathrm{C}$ under a constant current. From the results obtained from the initial three runs, it was found that the maximum deposited amount of $\mathrm{U}$ was $7.4 \mathrm{wt} \%$ $\mathrm{U} / \mathrm{Cd}$. U dendrite formation on the LCC crucible was not observed across each of the three runs. Three additional runs were conducted using LiCl-KCl- $\mathrm{UCl}_{3}-\mathrm{RECl}_{3}$ to determine the extent of $\mathrm{U} / \mathrm{RE}$ electrodeposition. The maximum number of moles of $\mathrm{U}+\mathrm{RE}$ metals deposited was 0.07 , a value estimated to be 2.14 times higher than the solubility limits exhibited by these metals in $\mathrm{Cd}$. The results of this study show that the use of a Cd stirrer significantly improves the extent of U deposition.
\end{abstract}

\section{Introduction}

The acute global issue concerning the accumulation of spent nuclear fuel (SNF) has accelerated the development of abatement technologies that reduce the volume of radioactive waste. Pyroprocessing is a technology that enables the extraction of useful nuclear elements from SNF for use in fast reactors. Its commercial viability was successfully demonstrated through the EBR-II (Experimental Breeder Reactor-II) project $[1,2]$. Pyroprocessing consists of several unit processes to separate and recover the radioactive elements from within the SNF [3, 4]. In the head-end process, the spent oxide fuel is separated from the hull, which then undergoes a heat treatment to achieve an appropriate size and density for the subsequent electrochemical processes. Subsequently, the processed spent oxide fuel is immersed in molten $\mathrm{Li}_{2} \mathrm{O}-\mathrm{LiCl}$ salt at $650^{\circ} \mathrm{C}$ and reduced via electrolytic reduction. From here, the reduced spent fuel undergoes an electrorefining process in a eutectic $\mathrm{LiCl}-\mathrm{KCl}$ melt with a predetermined volume of $\mathrm{UCl}_{3}$ at $500^{\circ} \mathrm{C}$ to facilitate uranium (U) recovery at the solid cathode. Subsequently, the residual $\mathrm{U}$ and transuranic elements (TRU) are recovered via electrowinning at the liquid cadmium cathode (LCC). After both electrorefining and electrowinning recovery steps have been applied, rare earth (RE) elements in the molten salt are treated to minimize salt waste and to facilitate the fabrication of a durable waste form. Among these unit processes, electrowinning is regarded as a key step owing to its nuclear proliferation resistance. Nuclear nonproliferation through the electrowinning process is achieved through the use of an LCC; however, an inevitable problem arises in the formation of $U$ dendrites at the surface of the LCC. If the volume of $U$ deposited exceeds the solubility limit of $\mathrm{U}$ in $\mathrm{Cd}$, the $\mathrm{U}$ dendrites expand into the electrolyte phase which hinders the codeposition of $U$ and TRU as it acts as a solid cathode. The problem arises as only $U$ can be deposited on the $U$ dendrites. In an attempt to solve this problem, a number of studies have focused on designing the LCC in such a way as 


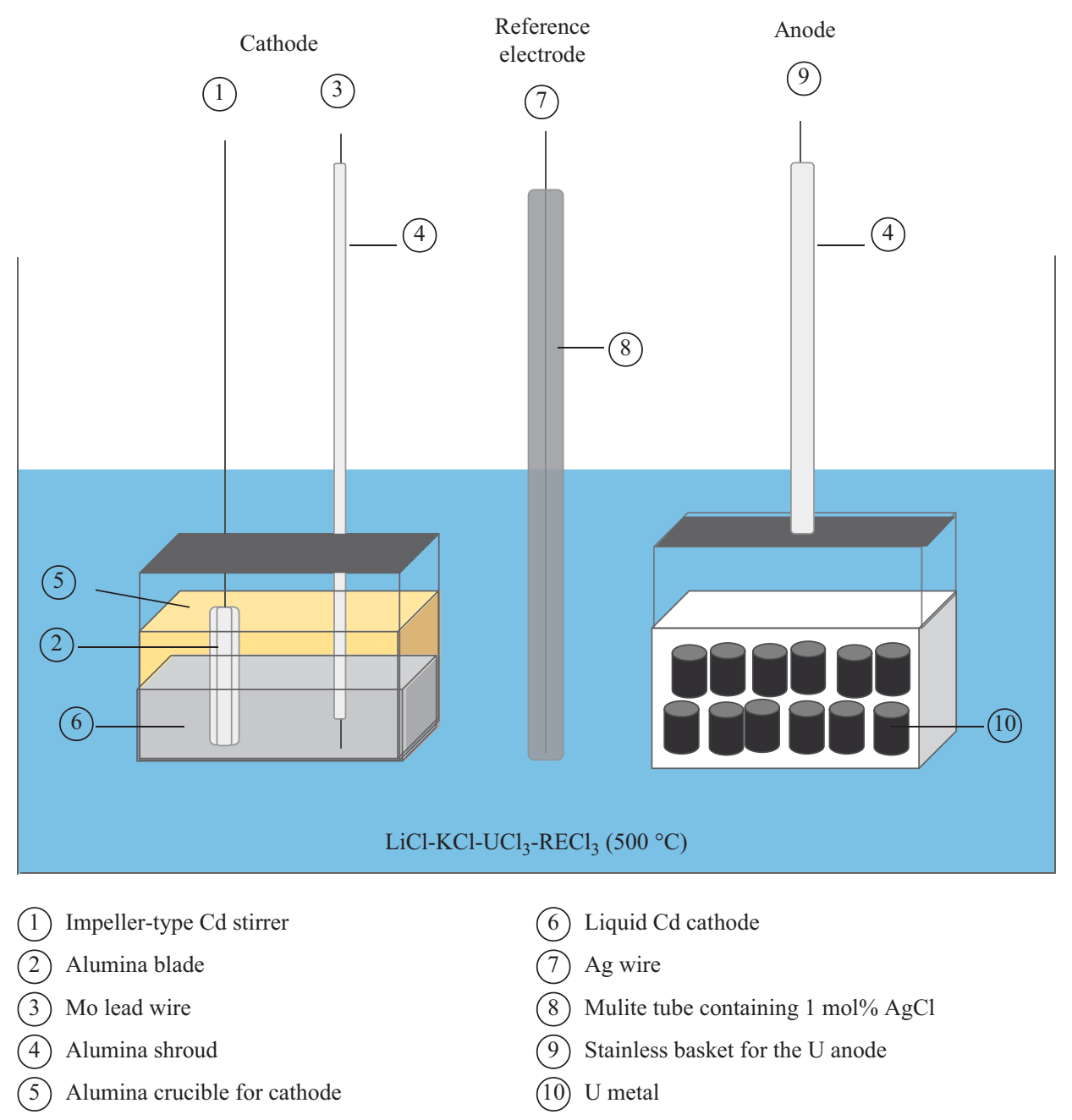

FIgURE 1: Schematic of the experimental setup.

to inhibit the formation of $U$ dendrites. In Japan, a paddletype stirrer was developed which prevented $U$ dendrite formation by introducing turbulent flow [5]. In the USA, a pounder-type LCC was designed which pushed any $U$ deposits down into the LCC [6]. At the Korea Atomic Energy Research Institute (KAERI), a mesh-type LCC structure was devised which allowed significant $U$ deposition of over $5 \mathrm{wt}$ $\%$ in the LCC without inducing $U$ dendrite formation [7]. In this study, a series of $U$ and $U / R E$ electrodeposition tests were performed, utilizing a stirred LCC. The Cd stirrer was designed to improve actinide recovery by preventing the formation and growth of $\mathrm{U}$ dendrites at the $\mathrm{Cd}$ surface. In order to evaluate the performance of the stirred LCC, electrodeposition experiments using the novel LCC with the $\mathrm{Cd}$ stirrer were conducted in $\mathrm{LiCl}-\mathrm{KCl}-\mathrm{UCl}_{3}$ and $\mathrm{LiCl}-\mathrm{KCl}-$ $\mathrm{UCl}_{3}-\mathrm{RECl}_{3}$ (RE: Nd, Ce, and La) at $500^{\circ} \mathrm{C}$.

\section{Materials and Methods}

All experiments were performed in a glove box under an $\operatorname{Ar}(\mathrm{g})$ atmosphere $\left(\mathrm{H}_{2} \mathrm{O}<1 \mathrm{ppm}\right.$ and $\left.\mathrm{O}_{2}<3 \mathrm{ppm}\right)$. The liquid $\mathrm{Cd}$ cathode was prepared in a rectangular alumina crucible. The crucible was used as the $\mathrm{Cd}$ container into which a lead wire and Cd stirrer were added in parallel, as shown schematically in Figure 1. The stirrer consisted of a three-blade impeller and a head motor (IG-32GM 03TYPE DC $12 \mathrm{~V}$ + encoder), with the areas in contact with Cd being fabricated from alumina. The $\mathrm{Cd}$ lead wire was insulated by an alumina shroud except for a portion of the bottom section. The reference electrode consisted of a Mullite tube into which the $\mathrm{LiCl}-\mathrm{KCl}$ eutectic mixture containing $1 \mathrm{~mol} \%$ $\mathrm{AgCl}$ was added. An Ag wire (1 mm diameter, Nilaco, Japan) was then immersed into the $\mathrm{LiCl}-\mathrm{KCl}-\mathrm{AgCl}$ salt. The stainless steel (SS) anode basket contained approximately $270 \mathrm{~g}$ of $\mathrm{U}$ pellets. The $\mathrm{U}$ electrodeposition tests (runs 1-3) were performed in $\mathrm{LiCl}-\mathrm{KCl}-2.85 \mathrm{wt} \% \mathrm{UCl}_{3}$ salt, which was prepared by adding $\mathrm{LiCl}-\mathrm{KCl}-10 \mathrm{wt} \% \mathrm{UCl}_{3}$ to $\mathrm{LiCl}-\mathrm{KCl}$ eutectic salt (99.99\% purity, Sigma-Aldrich). $\mathrm{UCl}_{3}$ was prepared via the reaction of $\mathrm{CdCl}_{2}$ with $\mathrm{U}$ metal in molten $\mathrm{LiCl}-\mathrm{KCl}$ at $500^{\circ} \mathrm{C}$, which produced a purple salt containing $10 \mathrm{wt} \% \mathrm{UCl}_{3}$ [8]. After the $\mathrm{U}$ electrodeposition tests had been performed, $\mathrm{RECl}_{3}$ (RE: $\mathrm{Nd}, \mathrm{Ce}$, and $\mathrm{La}, 99.99 \%$ purity, Alfa Aesar) was added to the salt for the U/RE electrodeposition tests (runs 4-6), which were performed in accordance with the initial conditions of the LCC electrowinning process shown in the KAERI flow sheet. The composition of 
TABLE 1: Salt composition for each of the U/RE electrodeposition tests.

\begin{tabular}{lcccc}
\hline & \multicolumn{3}{c}{${ }^{\mathrm{wt} \%}$} \\
& $\mathrm{UCl}_{3}$ & $\mathrm{NdCl}_{3}$ & $\mathrm{CeCl}_{3}$ & $\mathrm{LaCl}_{3}$ \\
\hline Runs 1-3 & 2.85 & - & - & - \\
Runs 4-6 & 2.76 & 1.98 & 0.81 & 0.42 \\
\hline
\end{tabular}

the prepared $\mathrm{LiCl}-\mathrm{KCl}$ salts containing $\mathrm{U}$ and $\mathrm{RE}$ elements is shown in Table 1. The metal chloride concentrations in the $\mathrm{LiCl}-\mathrm{KCl}$ eutectic melts were determined through inductively coupled plasma-atomic emission spectroscopy (ICPAES). The electrochemical experiments were performed using a Biologic SP-300 potentiostat/galvanostat. The electrodeposition tests were performed under a constant current density $\left(100 \mathrm{~mA} / \mathrm{cm}^{2}\right)$. At the end of the electrodeposition test, the LCC crucible was removed from the electrolyte bath and naturally cooled at room temperature. Subsequently, the Cd ingot, containing $U$ or U/RE deposits, was separated from the crucible. The mass of U or U/RE deposited onto the Cd surface was calculated based on the total charge transferred during each run, assuming 100\% current efficiency.

\section{Results and Discussion}

Prior to starting the LCC electrodeposition test, cyclic voltammetry $(\mathrm{CV})$ measurements were performed using the stirred LCC immersed in LiCl-KCl-2.85 wt $\% \mathrm{UCl}_{3}$ at $500^{\circ} \mathrm{C}$. Figure 2 shows the $\mathrm{CV}$ results obtained under various $\mathrm{Cd}$ stirring rates. It was observed that the $\mathrm{CV}$ curve was distorted by stirring $\mathrm{Cd}$. As the stirring rate of $\mathrm{Cd}$ increased, the cathodic peak potential exhibited a negative shift, while the peak current exhibited a positive increase. This was attributed to the surface enlargement of $\mathrm{Cd}$ induced through agitation. No further changes to the $\mathrm{CV}$ values were observed when the stirring rate surpassed $60 \mathrm{rpm}$. Thus, a Cd stirring rate of $60 \mathrm{rpm}$ was used throughout these experiments.

Three runs of the $\mathrm{U}$ electrodeposition tests were performed in $\mathrm{LiCl}-\mathrm{KCl}-2.85 \mathrm{wt} \% \mathrm{UCl}_{3}$ at $500^{\circ} \mathrm{C}$, under a constant applied current $\left(1.25 \mathrm{~A}, 100 \mathrm{~mA} / \mathrm{cm}^{2}\right)$. Run 1 was conducted for approximately $2.4 \mathrm{~h}$ and used $330 \mathrm{~g}$ of Cd. As shown in Figure 3, the anode's potential was maintained at $-1.10 \mathrm{~V}$, while the cathode's potential of $-1.62 \mathrm{~V}$ exhibited fluctuations as a result of the Cd stirring. After $2.39 \mathrm{~h}$, the cathode's potential shifted to a negative trajectory, and run 1 was terminated. The total amount of charge transferred was $4.19 \mathrm{Ah}$, and the amount of $\mathrm{U}$ deposited was calculated to be $3.76 \mathrm{wt} \% \mathrm{U} / \mathrm{Cd}$. This was 1.6 times higher than the $\mathrm{U}$ solubility limit in $\mathrm{Cd}$, which is $2.35 \mathrm{wt}$ $\%$ U/Cd. Despite the sharp decrease in the cathode potential recorded at the end of the test, there was no observable $U$ dendrite formation over the crucible (Figure 4).

Subsequently, two further $\mathrm{U}$ electrodeposition runs were performed at the same applied current. Run 2 used $335 \mathrm{~g}$ of $\mathrm{Cd}$ and was conducted for approximately $4.08 \mathrm{~h}$. The initial potential at the anode was $-1.1 \mathrm{~V}$, which gradually increased to $-0.9 \mathrm{~V}$. The potential at the cathode was $-1.7 \mathrm{~V}$ during the first $2 \mathrm{~h}$ of operation, which then gradually decreased to $-2.0 \mathrm{~V}$ at the end of the test (data not shown). The total amount of charge transferred was $5.09 \mathrm{Ah}$ which

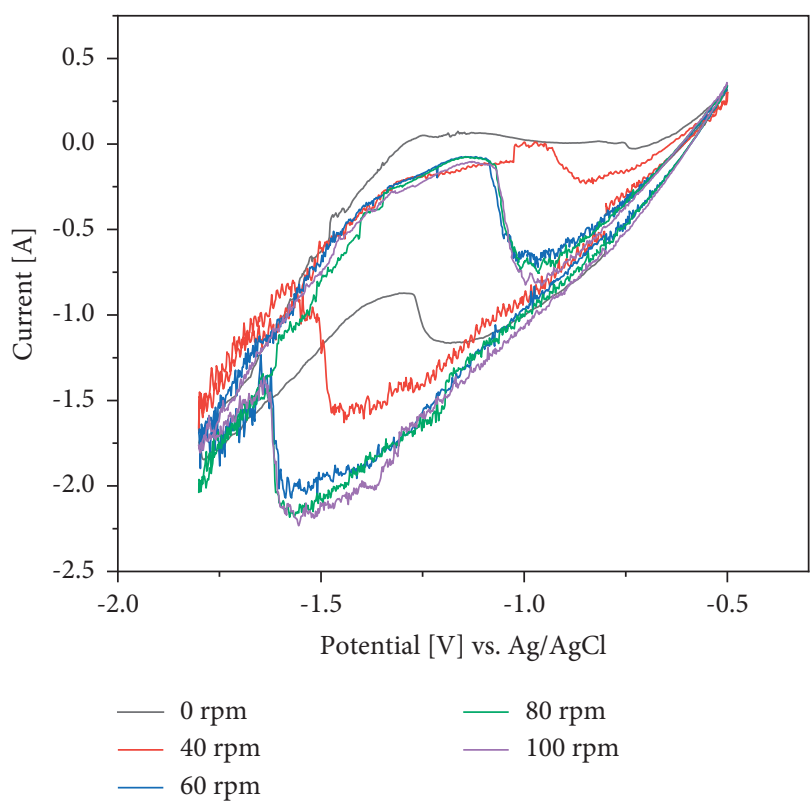

Figure 2: Cyclic voltammograms of the liquid Cd electrode in $\mathrm{LiCl}$ $\mathrm{KCl}-\mathrm{UCl}_{3}$ at $500^{\circ} \mathrm{C}$ with various $\mathrm{Cd}$ stirring rates.

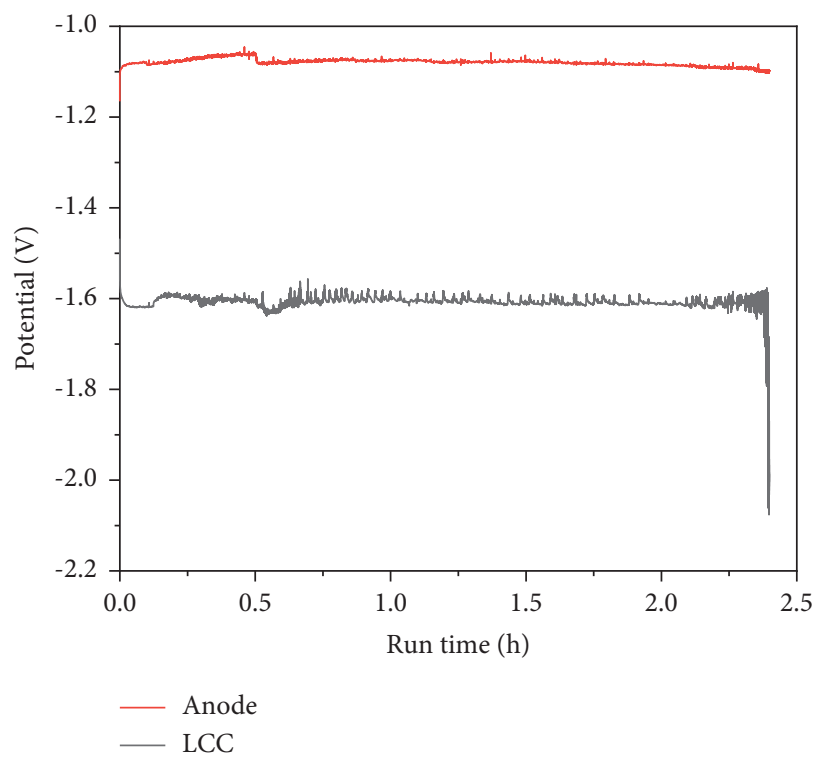

FIGURE 3: Potential profiles of run 1 using the stirred LCC immersed in $\mathrm{LiCl}-\mathrm{KCl}-\mathrm{UCl}_{3}$ at $500^{\circ} \mathrm{C}$.

corresponded to a deposition amount of approximately 4.5 wt\% U/Cd, a value 1.9 times higher than the solubility limit of $\mathrm{U}$ in $\mathrm{Cd}$. $\mathrm{U}$ dendrite formation was not observed on either the LCC crucible or the Cd surface. In contrast to runs 1 and 2 , run 3 was conducted using $200 \mathrm{~g}$ of Cd over a period of $4 \mathrm{~h}$. Owing to the constraints imparted by the physical environment, it was not possible to extend the period of time over which the test was performed. Therefore, it was necessary to reduce the initial mass of Cd to increase the extent of the electrodeposition ( $w t \%$ ) over the same time period. As shown in Figure 5, the cathode potential was in the range between -1.8 and $-1.9 \mathrm{~V}$ during the first $2 \mathrm{~h}$ of operation 


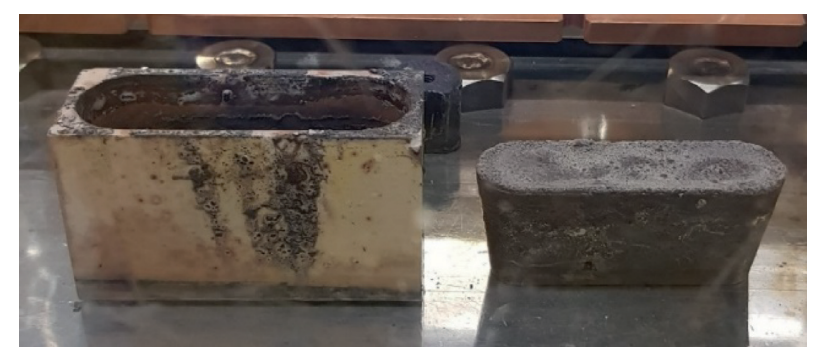

FIGURE 4: Photographs of the LCC crucible and Cd ingot after run 1.

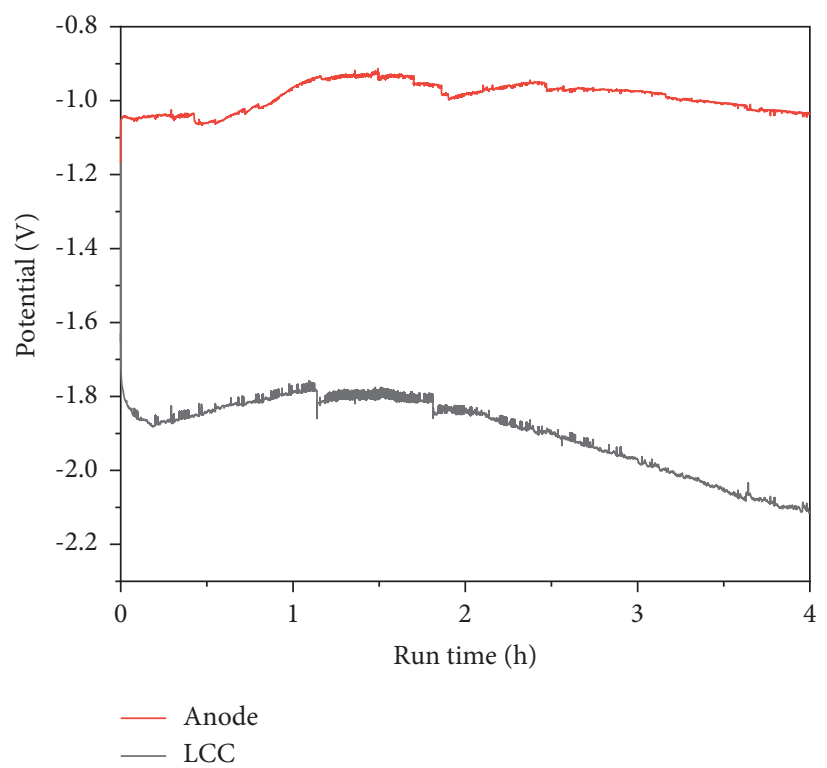

FIgURE 5: Potential profiles obtained during run 3 using the stirred $\mathrm{LCC}$ immersed in $\mathrm{LiCl}-\mathrm{KCl}-\mathrm{UCl}_{3}$ at $500^{\circ} \mathrm{C}$.

before continually decreasing over the remainder of the test period to reach $-2.1 \mathrm{~V}$. Throughout the test, the potential at the anode remained relatively stable around $-1.1 \mathrm{~V}$. The total amount of charge transferred was $5.00 \mathrm{Ah}$, which corresponded to an electrodeposition amount of approximately $7.4 \mathrm{wt} \% \mathrm{U} / \mathrm{Cd}$. This value is 3.0 times higher than the solubility limit of $\mathrm{U}$ in $\mathrm{Cd}$. The LCC product after run 3 is shown in Figure 6. In runs $1-3$, U dendrites on $\mathrm{Cd}$ and/or over the LCC crucible were not found, which is confirmed by the photographs of LCC products (Figures 4 and 6). It was proved by no increasing of the cathodic potentials during the electrodeposition of $U$ (Figures 3 and 5). This indicates there was no variation of $\mathrm{Cd}$ surface area induced by the formation of $U$ dendrites. If there was any growth of $U$ dendrite, it would either sink or be crushed into Cd by operating the $\mathrm{Cd}$ stirrer. Each of the results, including the deposited mass of metal across runs 1-6, is summarized in Table 2.

After each of the $U$ electrodeposition tests had been completed, three U/RE electrodeposition runs were performed in the same manner using $\mathrm{LiCl}-\mathrm{KCl}-\mathrm{UCl}_{3}-\mathrm{RECl}_{3}$. Run 4 used $101 \mathrm{~g}$ of $\mathrm{Cd}$, and a constant current of $1.25 \mathrm{~A}$ was applied for approximately $2 \mathrm{~h}$ (data not shown). The initial cathode potential was $-1.8 \mathrm{~V}$, which incrementally increased to $-1.2 \mathrm{~V}$ before stabilizing at $-1.6 \mathrm{~V}$. The anode potential repeatedly and periodically fluctuated before stabilizing around $-1.0 \mathrm{~V}$.
The total amount of charge transferred was $2.50 \mathrm{Ah}$. Run 5 used $106 \mathrm{~g}$ of $\mathrm{Cd}$ and was conducted for $2.5 \mathrm{~h}$. The potential at the anode was maintained at $-1.3 \mathrm{~V}$, while the potential at the cathode was maintained at $-1.6 \mathrm{~V}$ (data not shown). The total amount of charge transferred during run 5 was $3.75 \mathrm{Ah}$. Finally, run 6 used $105 \mathrm{~g}$ of $\mathrm{Cd}$ and was conducted for $3.8 \mathrm{~h}$ (Figure 7 ). The anode potential fluctuated over a $0.50 \mathrm{~h}$ cycle during the initial $1.67 \mathrm{~h}$ of operation before stabilizing at $-0.55 \mathrm{~V}$. The initial cathode potential was approximately $-1.8 \mathrm{~V}$. This potential exhibited significant fluctuations during the first $1.00 \mathrm{~h}$ of operation before increasing slightly to $-1.6 \mathrm{~V}$ for the remainder of the test. The total amount of charge transferred in run 6 was $5.69 \mathrm{Ah}$. As both $\mathrm{U}$ and RE were deposited onto the LCC during the U/RE electrodeposition tests (runs 4-6), it was necessary to convert the total amount of charge transferred across runs 4-6 to the number of moles of the electrodeposited metal. Considering this conversion, the total number of moles of $\mathrm{U}+\mathrm{RE}$ deposited across runs 4-6 was $0.031,0.047$, and 0.071 , respectively. These values were compared with the solubility limits of the metals in $\mathrm{Cd}$ at $500^{\circ} \mathrm{C}$ (Table 3) [9]. By considering the weight of Cd used in each run, it was determined that a volume corresponding to the solubility limit was electrodeposited during run 4. During runs 5 and 6 , the volume of the electrodeposited metal $(\mathrm{U}+\mathrm{RE})$ exceeded the solubility limit by 1.40 and 2.14 times, 

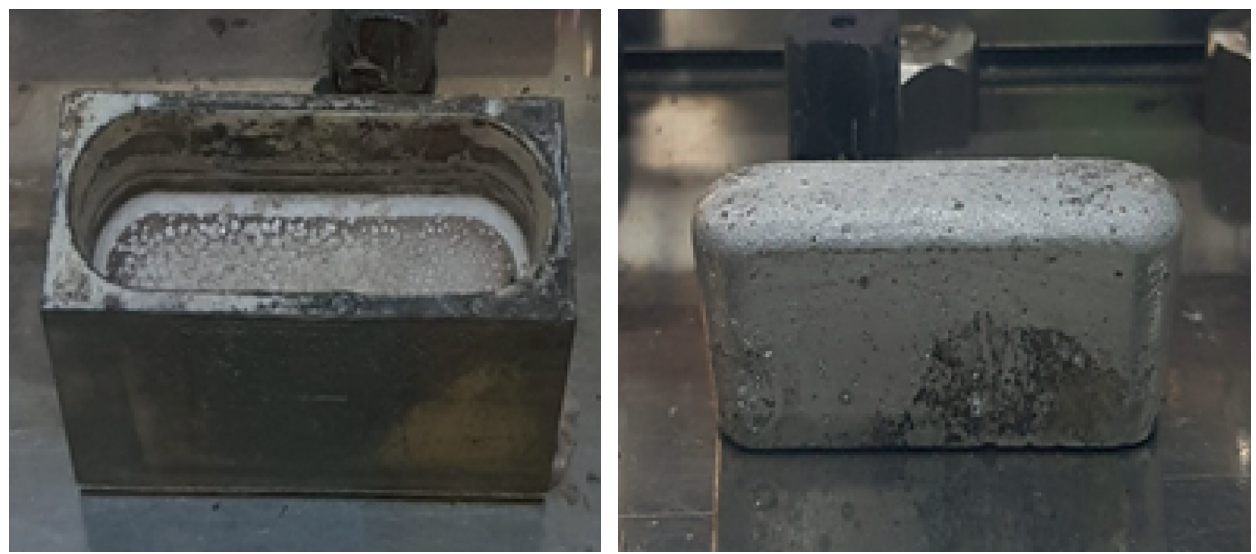

FIGURE 6: Photographs of the LCC crucible and Cd ingot after run 3.

TABLE 2: Results of electrodeposition runs 1-6 in this study.

\begin{tabular}{lccc}
\hline Run no. & Cd (g) & Q (Ah) & Assumption: current efficiency of 100\% \\
$(\mathrm{U}+\mathrm{RE})_{\text {deposited }} /(\mathrm{U}+\mathrm{RE})_{\text {saturated }}$
\end{tabular}

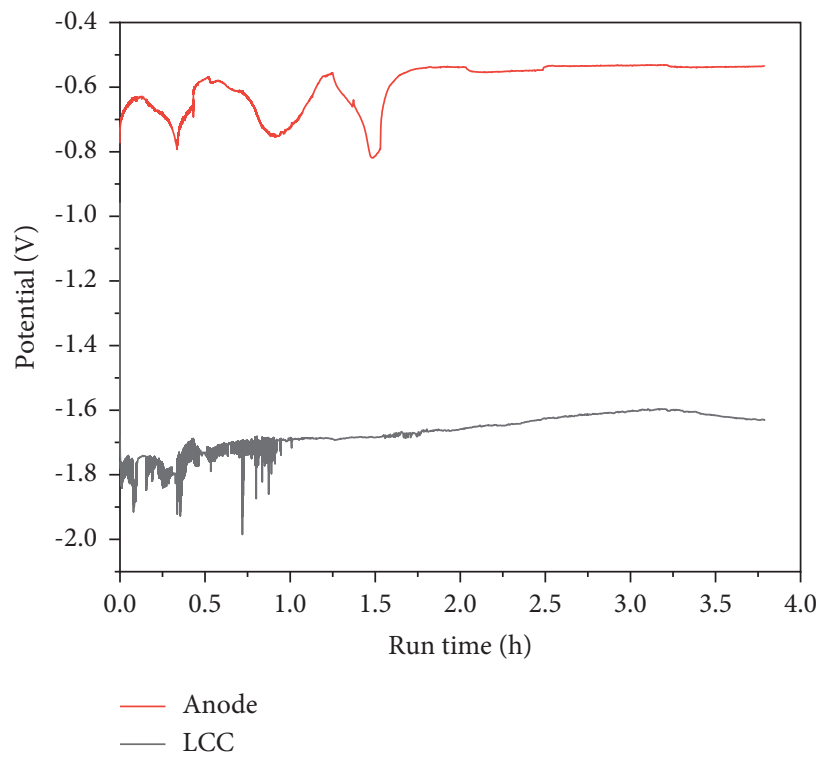

FIgURe 7: Potential profiles gathered during run 6 using the stirred LCC immersed in $\mathrm{LiCl}-\mathrm{KCl}-\mathrm{UCl}_{3}-\mathrm{NdCl}_{3}-\mathrm{CeCl}_{3}-\mathrm{LaCl}_{3}$ at $500^{\circ} \mathrm{C}$.

TABLE 3: Solubility limit of metal elements in $\mathrm{Cd}$ at $500^{\circ} \mathrm{C}[9]$.

\begin{tabular}{lccc}
\hline \multirow{2}{*}{ Element } & & \multicolumn{2}{c}{ Solubility limit } \\
& wt\%/Cd & $\mathrm{g}$ (based on Cd 100 g) & Number of moles (based on Cd 100 g) \\
\hline $\mathrm{U}$ & 2.35 & 2.35 & 0.0099 \\
$\mathrm{Nd}$ & 1.89 & 1.89 & 0.0131 \\
$\mathrm{Ce}$ & 0.754 & 0.754 & 0.0054 \\
$\mathrm{La}$ & 0.4 & 0.4 & 0.0029 \\
\hline
\end{tabular}




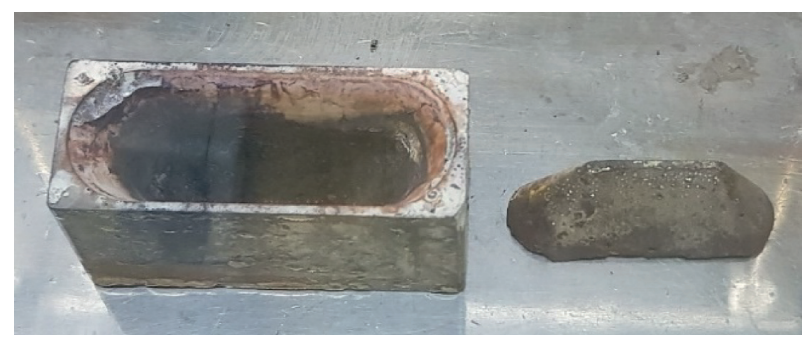

FIGURE 8: Photographs of the LCC crucible and Cd ingot after run 6.

respectively. After the tests had ended, the Cd ingots which had been subjected to U/RE deposition were easily and distinctly separated from their alumina crucibles, and there was no $\mathrm{U}$ dendrite formation observed in each ingot (Figure 8).

\section{Conclusions}

The effect of the stirred LCC on the electrowinning performance was evaluated by the extent of the electrodeposition exhibited by LiCl-KCl salts containing $\mathrm{U}$ or U/RE at $500^{\circ} \mathrm{C}$. Three tests were performed using $\mathrm{LiCl}-\mathrm{KCl}-\mathrm{UCl}_{3}$ (runs 1-3), and the amount of deposited $\mathrm{U}$ was estimated as 3.8 , 4.5, and $7.4 \mathrm{wt} \% \mathrm{U} / \mathrm{Cd}$, across runs 1,2 , and 3 , respectively. The formation of $\mathrm{U}$ dendrites on the LCC crucible was not observed in any of the three runs. Considering that the solubility limit of $\mathrm{U}$ in $\mathrm{Cd}$ is $2.35 \mathrm{wt} \% \mathrm{U} / \mathrm{Cd}$, it was possible to determine that the use of a $\mathrm{Cd}$ stirrer facilitated an increase in the efficiency of $U$ recovery. Three additional electrodeposition tests (runs 4-6) were performed using $\mathrm{LiCl}-\mathrm{KCl}-\mathrm{UCl}_{3}-\mathrm{RECl}_{3}$ under an applied current density of $100 \mathrm{~mA} / \mathrm{cm}^{2}$. The number of moles of the metal (U, Nd, Ce, and $\mathrm{La}$ ) deposited on $\mathrm{Cd}$ was $0.031,0.047$, and 0.071 , across runs 4,5 , and 6 , respectively. These values were compared with the solubility limits exhibited by each metal in Cd. According to the results, the amounts of metal ( $U$ and $R E$ ) deposited on $\mathrm{Cd}$ were between 1.00 and 2.14 times higher than the proposed solubility limits in $\mathrm{Cd}$. Although these results were obtained through calculations rather than chemical analysis, it was found that the use of a Cd stirrer enhanced the LCC performance during the electrowinning process through the inhibition of $U$ dendrite formation.

\section{Data Availability}

The data used to support the findings of this study are included within the article.

\section{Conflicts of Interest}

The authors declare that there are no conflicts of interest regarding the publication of this paper.

\section{Acknowledgments}

This work was supported by the Korea Atomic Energy Research Institute (KAERI) R\&D Program of the Korean Ministry of Science and ICT (MSIT) (Grant no. 521150-21), the Institute for Korea Spent Nuclear Fuel (iKSNF) and National Research Foundation of Korea (NRF) Grant funded by the Korea Government (Ministry of Science and ICT, MSIT) (Grant no. 2021M2E1A1085193), and Nuclear Research and Development Program (Grant no. 2021M2E3A2041351) by the National Research Foundation of Korea.

\section{References}

[1] J. J. Laidler, J. E. Battles, W. E. Miller, J. P. Ackerman, and E. L. Carls, "Development of pyroprocessing technology," Progress in Nuclear Energy, vol. 31, no. 1-2, pp. 131-140, 1997.

[2] C. E. Till and Y. I. Chang, Plentiful Energy: The Story of the Integral Fast Reactor, Create Space Independent Publishing Platform, Scotts Valley, CA, USA, 2011.

[3] H.-S. Lee, G.-I. Park, K.-H. Kang et al., "Pyroprocessing technology development at KAERI," Nuclear Engineering and Technology, vol. 43, no. 4, pp. 317-328, 2011.

[4] T. Inoue and L. Koch, "Development of pyroprocessing and its future direction," Nuclear Engineering and Technology, vol. 40, no. 3, pp. 183-190, 2008.

[5] T. Koyana, M. Iizuka, Y. Shoji et al., “An experimental study of molten salt electrorefining of uranium using solid iron cathode and liquid cadmium cathode for development of pyrometallurgical reprocessing," Journal of Nuclear Science and Technology, vol. 34, no. 4, pp. 384-393, 1997.

[6] E. Vaden, B. R. Westphal, S. X. Li, and T. A. Johnson, International Pyroprocessing Research Conference, IPRC 2006, Idaho University Center, Idaho Falls, ID, USA, 2006.

[7] S. Paek, S.-H. Kim, D.-S. Yoon, H. Lee, and D.-H. Ahn, "Performance of the mesh-type liquid cadmium cathode structure for the electrodeposition of uranium from the molten salt," Radiochimica Acta, vol. 98, no. 12, pp. 779-783, 2010.

[8] G.-Y. Kim, D. Yoon, S. Paek, S.-H. Kim, T.-J. Kim, and D.-H. Ahn, "A study on the electrochemical deposition behavior of uranium ion in a $\mathrm{LiCl}-\mathrm{KCl}$ molten salt on solid and liquid electrode," Journal of Electroanalytical Chemistry, vol. 682, pp. 128-135, 2012.

[9] M. Kurata, Y. Sakamura, and K. Kinoshita, "Distribution behavior of uranium, neptunium, rare-earth elements (Y, La, Ce, $\mathrm{Nd}, \mathrm{Sm}, \mathrm{Eu}, \mathrm{Gd}$ ) and alkaline-earth metals ( $\mathrm{Sr}, \mathrm{Ba}$ ) between molten $\mathrm{LiCl}-\mathrm{KCl}$ eutectic salt and liquid cadmium or bismuth," Journal of Nuclear Materials, vol. 227, no. 1-2, pp. 110-121, 1995. 